\title{
Feto maternal outcome in obstructed labor: a tertiary centre study
}

\author{
Anshul Bansal, Ruchi Kalra* \\ Department of Obstetrics and Gynecology, People's College of Medical Sciences and Research Centre, Bhopal, \\ Madhya Pradesh, India
}

Received: 16 April 2019

Accepted: 22 May 2019

*Correspondence:

Dr. Ruchi Kalra,

E-mail: drruchi.kalra15@gmail.com

Copyright: ( $)$ the author(s), publisher and licensee Medip Academy. This is an open-access article distributed under the terms of the Creative Commons Attribution Non-Commercial License, which permits unrestricted non-commercial use, distribution, and reproduction in any medium, provided the original work is properly cited.

\begin{abstract}
Background: The number of maternal deaths as a result of obstructed labor is $8 \%$ globally but this number varies in developing country, it ranges $4-70 \%$ of all maternal deaths and it is also associated to high perinatal mortality rate. Objective of the study was to find out the proportion of obstructed labour cases and their feto-maternal outcome during last 3 years at tertiary level institute.

Methods: A cross sectional observation study was done at Department of Obstetrics and Gynecology, People's College of Medical Sciences and Research Centre Bhopal. All pregnant women presenting with obstructed labor who delivered at our hospital during last 3 years duration (January 2015 to December 2017) were studied for their feto maternal outcome.

Results: 53\% cases had duration of trail more than 16 hours. $84 \%$ were referred from primary health centers of nearby rural areas. All cases of obstructed labor delivered by cesarean section (100\%). $44 \%$ were primigravida. $72 \%$ of cases had Cephalopelvic disproportion as the cause. $28 \%$ of cases had longer stay more than 7 days at hospital. $32 \%$ had fever during post operative period $12.5 \%$ cases had wound sepsis and $6 \%$ of cases required re-suturing of wound during post operative period. $72 \%$ baby's birth weight was between 3 to $3.4 \mathrm{~kg}$. $94 \%$ of the babies survived where as $6 \%$ of babies were still birth. $16 \%$ of babies born to obstructed labor mother had APGAR less than 7 at 5 minutes of birth. $6 \%$ fetus were IUFD.

Conclusions: Cephalopelvic disproportion was the most common cause for obstructed labor. Timely identification of prolonged labor and timely referral and management at place where operation theatre, NICU and blood bank facilities are available can save the life of both baby and mother.
\end{abstract}

Keywords: Fetal death, Maternal morbidity, Obstructed labor, Postnatal complications

\section{INTRODUCTION}

George Dunea and Einar Perman reported a historical event "Princess Charlotte became pregnant in early 1817 at the age of 21, having miscarried twice in the previous year. She survived being starved and occasionally bled by her doctors according to the misguided practices of the time. The delivery itself was protracted, her cervix slows to dilate, the baby large and in a transverse position, the royal physicians adhering to the school of thought that favored a conservative approach and brooked no intervention. Exhausted, deprived of analgesics according to the practice of the day, she delivered a dead fetus after 50 hours in labor and died soon thereafter from postpartum hemorrhage.

Even according to the medical standards of the time the case was considered to have been mishandled, and two years later her physician committed suicide." ${ }^{1}$ This royal case signifies the grave outcome of obstructed labor. As 
per WHO obstructed labour 'the presenting part to the fetus is not able to pass into the birth canal despite strong uterine contractions'.

The number of maternal deaths as a result of obstructed labour is $8 \%$ globally but this number varies in developing country, it ranges $4-70 \%$ of all maternal deaths and it is also associated to high prenatal mortality rate. Ranjana and Anjana reported in their study done 2017 incidence of obstructed labor as $8.9 \% .^{3-5}$

Objective of the study was to find out the proportion of obstructed labour cases and their clinical profile and fetomaternal outcome during last 3 years at tertiary level institute. To study the proportion of cases of obstructed labor in last 3 years at tertiary care centre. To study maternal clinical profile and feto maternal outcome in the obstructed labor cases delivering at the Institute during study period.

\section{METHODS}

A cross sectional observation study was done at Department of Obstetrics and Gynecology, People's College of Medical Sciences and Research Centre Bhopal. All pregnant women who had features of obstructed labor and delivered at our hospital during last 3 years duration (January 2015 to December 2017) were studied for their clinical profile and feto-maternal outcome.

\section{The study variables for maternal profile and outcome were}

- Duration of labor trial

- Place of labor trial

- Mode of delivery (LSCS/Ventuse/Forceps)

- Parity of patients

- Causes of obstruction

- Blood components required for transfusion

- Postnatal occurrence of sepsis (criteria-Fever/Wound sepsis/Wound re-suturing)

- Duration of hospital stay.

\section{To study variables for the fetal outcome were}

- Birth weight

- $\quad$ APGAR Score at $5 \mathrm{~min}$.

- NICU admission

- Ventilator supports

- Duration of stay in NICU

- Neonatal outcome at discharge - Alive /died Fischer Exact test was used for statistical calculation.

\section{Inclusion criteria}

- All pregnant women in labor with features of obstructed labor Features suggesting obstructed labor which were taken into consideration were -
Duration of active phase of labor longer than $>12$ hours in Primi -gravida and 8 hours in multi gravida was criteria for prolonged first stage of labour. Prolonged second stage is more than 1hour in multi gravida and 2 hours in Primigravida

- Those patients with prolonged labour and having maternal distress with signs and symptoms of maternal exhaustion, dehydration, keto acidosis, Maternal signs shows Pulse $>100$ beats /min, raised body temperature, concentrated urine. On examination of abdomen Bandl's ring formation may be seen. On perineal examination Vulval oedema is present, vagina is hot and dry. Pelvic examination may reveals fetal caput.

\section{Exclusion criteria}

- All pregnant women who delivered (both vaginal and cesarean section) at our hospital without features of obstructed labor.

\section{RESULTS}

The proportion of obstructed labor cases delivered during 3 years of study period from $1^{\text {st }}$ January 2015 till $31^{\text {st }}$ December 2017 at our tertiary level institute were 32 cases of obstructed labor and 1963 cases were non obstructed deliveries. Thus proportion of obstructed labor was 1.6.

\section{Duration of labor trial}

Of all the cases of obstructed labor $16 \%$ cases had labor trial for less than 8 hours. $31 \%$ cases had duration of trial between 8-16 hours and 53\% cases had duration of trail more than 16 hours (Figure 1). Hence the range of duration of labor trial was from 8 hours to 16 hours in which more than half of the labor trials were of 16 hours and more duration.

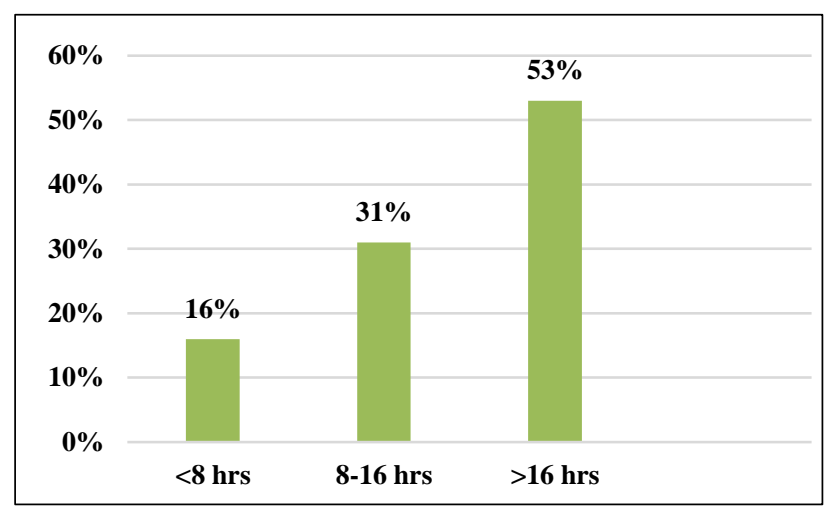

Figure 1: Duration of labor trial.

\section{Place of labor trial}

All the cases of obstructed labor were referral cases. 84\% were referred from primary health centers of nearby rural areas which suggests that more than two thirds of 
obstructed cases were referred from primary health centers. Rest $16 \%$ i.e. less than $1 / 3^{\text {rd }}$ of the cases were referred from local hospitals (Figure 2).

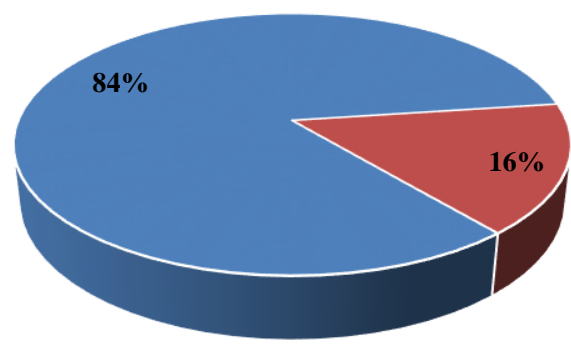

" Primary Health Centre - Local Hospitals

Figure 2: Place of labor trial.

\section{Mode of delivery (LSCS/Ventuse/forceps)}

All cases of obstructed labor delivered by caesarean section. $(100 \%)$ at our institute. There was no maternal mortality.

\section{Parity of cases with obstructed labor}

About $44 \%$ were primigravida, $41 \%$ cases were para 2 and para 3 and rest of $15 \%$ cases were para 4 and above. Least no. of cases were of para 4 and above whereas almost equal no. of cases were of primigravida and para 2 and 3 (Figure 3).

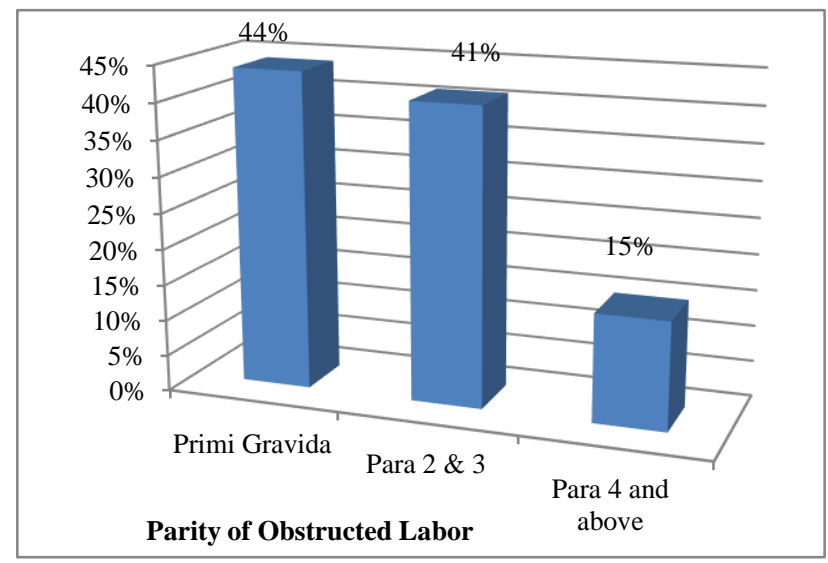

Figure 3: Parity distribution of obstructed labor cases.

\section{Causes of obstruction}

About $72 \%$ of cases had Cephalopelvic disproportion, Malposition was the cause in $28 \%$ cases commonest being occipito posterior position with deep transverse arrest. Therefore almost $2 / 3^{\text {rd }}$ of cases had cephalopelvic disproportion whereas around $1 / 4^{\text {th }}$ cases had malposition common being occipitoposterior position (Figure 4).

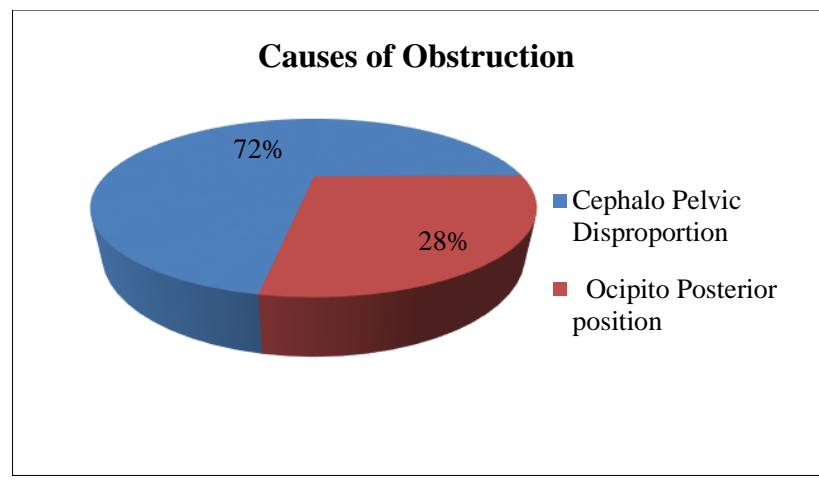

Figure 4: Causes of obstructed labor

\section{Blood components required for transfusion}

Only $16 \%$ cases required blood and blood components and rest of $84 \%$ of the cases did not required. Hence a very less number of cases required blood and blood components (Figure 5).

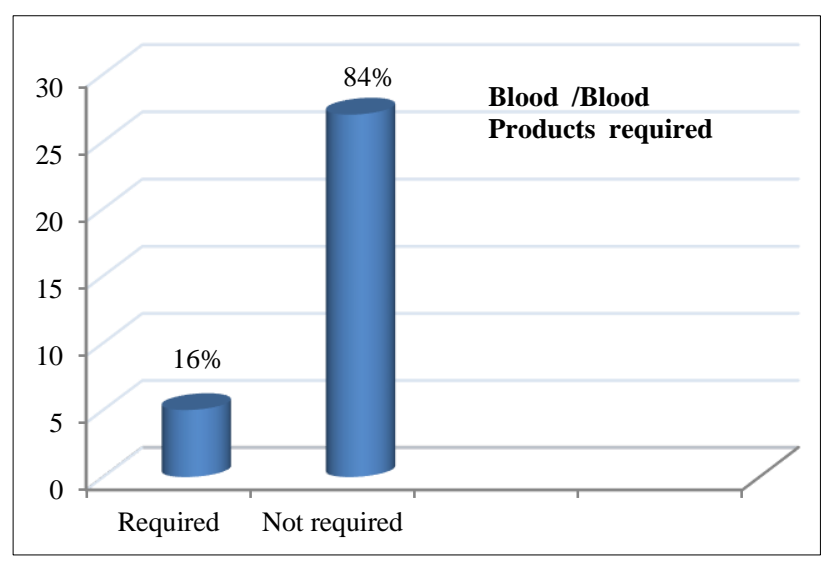

Figure 5: Blood products required.

\section{Hospital stay}

About $28 \%$ of cases had longer stay which was more than 7 days at hospital and $72 \%$ cases stay was 7 days or less. Most of the cases had normal stay of less than 7 days whereas around $1 / 4^{\text {th }}$ cases required a stay of more than 7 days at hospital (Figure 6).

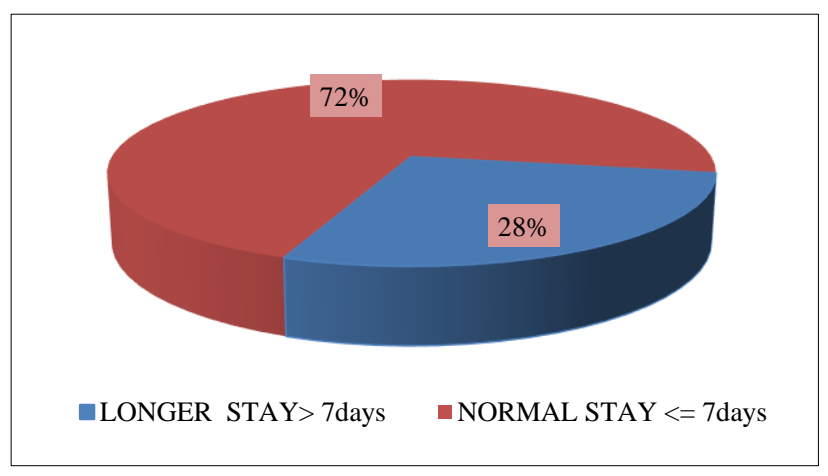

Figure 6: Hospital stay duration. 


\section{Occurrence of postnatal complications}

About $32 \%$ had developed fever during post operative period $12.5 \%$ cases had wound sepsis and $6 \%$ of cases required re-suturing of wound during post operative period. Overall $50.5 \%$ cases had some kind of complication during postnatal period in which highest number of cases had fever as a postnatal complication followed by wound sepsis (Figure 7).

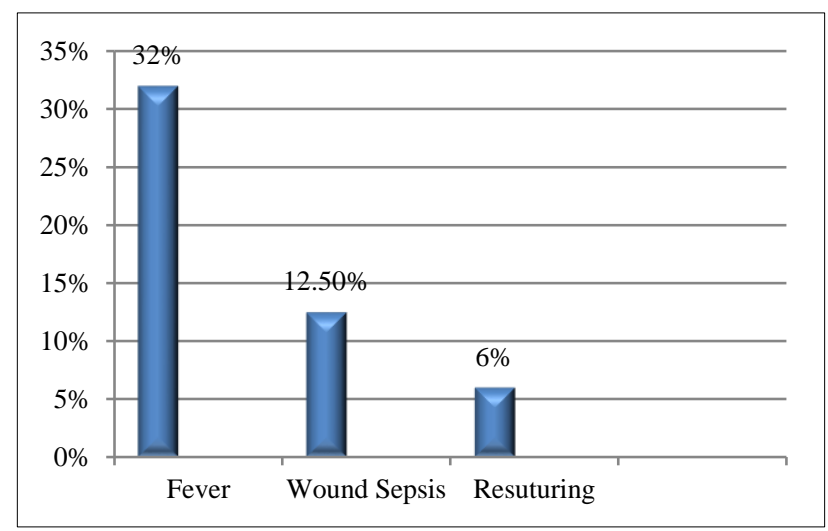

Figure 7: Incidence of post natal sepsis.

\section{Age distribution of cases}

Out of total cases 7 cases $(21.8 \%)$ were between $18-23$ age group, 20 cases (62.5\%) were between 24-29 years age group, 5 cases $(15.6 \%)$ were between $30-35$ years age group. Hence most of the cases were between 24-29 years age group while least no. of cases belong to 30-35 years age group (Figure 8).

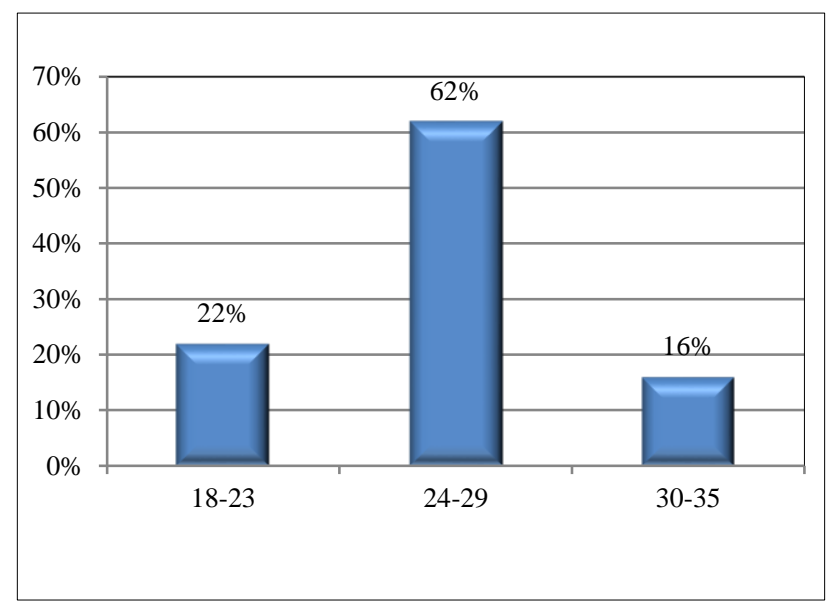

Figure 8: Age distribution of obstructed labor cases.

\section{Baby weight distributions}

About $19 \%$ babies had birth weight between 2.5 to $2.9 \mathrm{~kg}$. $72 \%$ baby's birth weight was between 3 to $3.4 \mathrm{~kg}$ and $1 \%$ cases baby's birth weight was more than $3.5 \mathrm{~kg}$. A much higher proportion of delivered babies had their weights in the ranges of 3-3.4 kgs followed by $2.5-2.9 \mathrm{kgs}$. Only $1 \%$ babies had their body weights more than $3.5 \mathrm{kgs}$ (Figure 9).

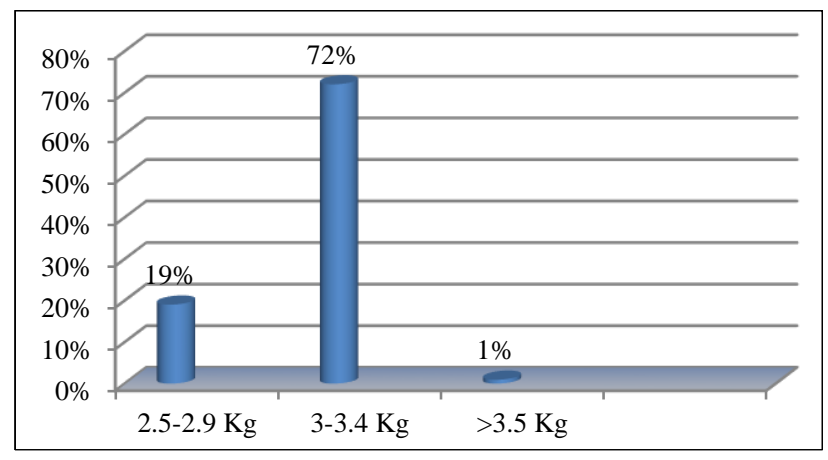

Figure 9: Baby weight distribution.

\section{Neonatal survival}

Of the total cases $94 \%$ of the babies survived where as $6 \%$ of babies were stillbirths. Hence by timely delivery by caesarean section most of the babies delivered were live births however very few deliveries were still birth (Figure 10).

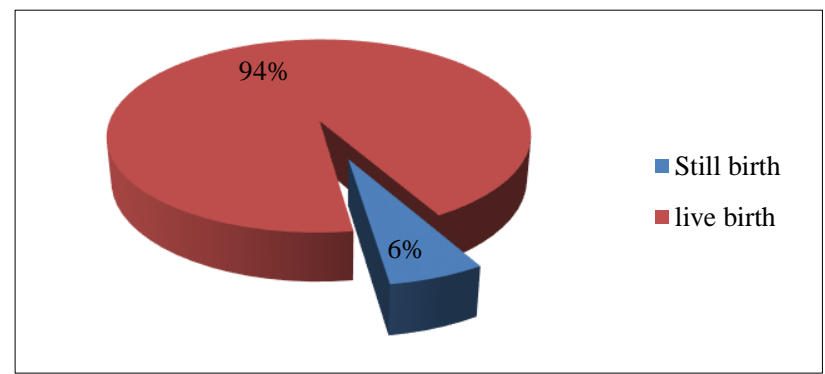

Figure 10: Neonatal survival percentage.

$16 \%$ of babies born to obstructed labor mother had APGAR at 5 min less than 7 and $84 \%$ babies APGAR Score was more than 7 (Figure 11). More than two-third of the cases had APGAR score of more than 7 at 5 min of birth.

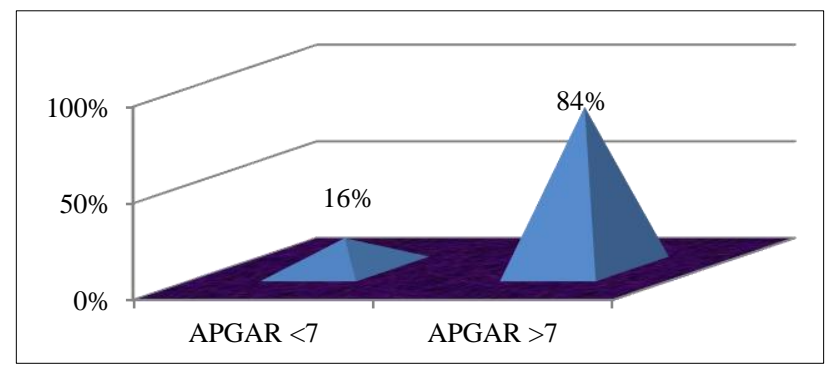

Figure 11: Apgar score at 5 mins of birth.

Of the total babies delivered to mothers with obstructed labour $44 \%$ of babies required NICU admission which accounts to slightly less than $50 \%$. More than half $(56 \%)$ of the delivered babies of obstructed labour did not require any NICU admission (Figure 12). 


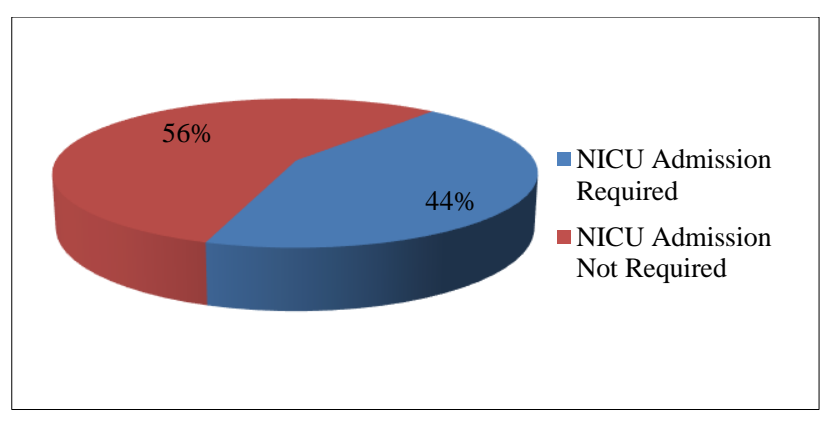

Figure 12: Neonates requiring NICU admission.

We have studied association between maternal age groups and baby outcome due to obstructed labour. It was seen that most of the alive babies belong to the age group of 24-29 year wheras 30-35 year age group had least number of alive cases. When this was compared against IUFD cases which were less in 18-23 and 24-29 years age groups. But this association was statistically non significant $(\mathrm{p}=0.56)($ Table 1$)$.

We studied association between refferal of pregnant mother for obstructed labour and baby outcome and it was found that most of the cases which were referred from private hospitals had alive babies $(83.3 \%)$. This was quite significantly higher than referred cases from PHCs which had IUFD. This relationship was statistically significant. $(\mathrm{p}=0.04 *)$ Statistical analysis was done using Fischer Exact test (Table 2).

Table 1: Association between maternal age and baby outcome.

\begin{tabular}{|c|c|c|c|c|}
\hline \multicolumn{5}{|c|}{ Baby outcome } \\
\hline Age group & Alive (N) & Alive (\%) & IUFD (N) & IUFD (\%) \\
\hline $8-23$ years & 6 & $20 \%$ & 1 & $50 \%$ \\
\hline 24-29 years & 19 & $63.3 \%$ & 1 & $50 \%$ \\
\hline $30-35$ years & 5 & $16.70 \%$ & 0 & $0 \%$ \\
\hline$P$ value & 0.56 & Fischer's ex & & Not significant \\
\hline
\end{tabular}

Table 2: Association between referral and baby outcome.

\begin{tabular}{|lllll|}
\hline Baby outcome & Alive (N) & Alive (\%) & IUFD (N) & IUFD (\%) \\
\hline Referral & 25 & $83.3 \%$ & 2 & $100 \%$ \\
\hline PHC & 5 & $16.7 \%$ & 0 & $0 \%$ \\
\hline Private hospital & $0.04 *$ & Fischer's exact test & Significant \\
\hline
\end{tabular}

Table 3: Association between maternal parity and baby outcome.

\begin{tabular}{|lllll|}
\hline Baby outcome & Alive (N) & Alive (\%) & IUFD (N) & IUFD (\%) \\
\hline Parity & 17 & $56.7 \%$ & 1 & $50 \%$ \\
\hline Multigravida & 13 & $43.3 \%$ & 1 & $50 \%$ \\
\hline Primigravida & $0.034 *$ & Fisher's exact test & & $*$ Significant \\
\hline P Value & & & 1 \\
\hline
\end{tabular}

We also studied association between maternal parity and baby outcome in obstructed labor cases. In multigravida category more than $50 \%$ cases ie. 17 cases had delivered live fetus whereas in primigravida category 13 had delivered live fetus. When this compared from IUFDs, only 1 case was found in both multigravida and primigravida categories. This association was also statistically significant. $(\mathrm{p}=0.034 *)$ Statistical analysis was done using Fischer exact test (Table 3 ).

\section{DISCUSSION}

Henok A et al, has done a study reporting from south west Euthopia in 2015. ${ }^{6}$ Prevalence of obstructed labour in their study was $7.95 \%$. They also reported cephalo pelvic disproportion as the leading cause of obstruction
(66.67\%), malpresentation and malposition (25\%) and cervical and congenital anomalies $(8.33 \%)$. The study also emphasized on good antenatal care as most of their cases were unbooked and good referral system to prevent the occurrence of complications.

Another study done by Ileogben Sunday Adeyoe who have reported a multi centric study done at south east Nigeria. ${ }^{7}$ The study reported most of the women were in age group 20-34 years. 33\% were Primi and $62.7 \%$ were referred from private Hospital. In our study the majority of referrals were from primary health centers $(84 \%)$ and only $16 \%$ were from local hospitals.

Another study reported from Karnataka by Indra et al, also reported percentage of Primi gravida was highest. ${ }^{8}$ 
They also had more referrals from peripheral areas. This points towards need for capacity building at PHC level for early identification and timely referral of the prolonged labour to prevent obstruction and its sequels.

Ranjana et al, reported from Bihar, incidence of obstructed labour as $8.9 \% .{ }^{9}$ In their study malposition $(45.61 \%)$ and cephalopelvic disproportion (43.85\%). Cesarean section was the commonest mode of delivery. $21.92 \%$ case rupture uterus was diagnosed before the surgery and in $2.63 \%$ cases had scar rupture. In their study PPH occurred in $17.4 \%$ cases. Maternal mortality was $3.5 \%$ and perinatal mortality was $39 \%$. In our study there was no maternal mortality and still birth was $6 \%$.

Khatun $\mathrm{J}$, in the study reported Primi gravida had highest incidence. ${ }^{10}$ Majority (78\% cases) had CPD as the cause. Cesarean section was done in $95 \%$ of the cases.

Sheikh SR, in the study reported $3.61 \%$ of obstructed labor in the study. $90.9 \%$ case delivered by cesarean section. ${ }^{11}$ No mortality occurred in their study.

Joseph $\mathrm{N}$ has done a study in 2018 on 272 obstructed labour women. ${ }^{12}$ Vaginal swab was taken to determine vaginal colonization with GBS, E. Coli and Enterococcus and associated morbidity was studied by them. They reported $64 \%$ obstructed labour women were colonized with the $49 \%$ with E.Coli, 5\% with GBS and $8 \%$ with Enterococcus. The study reported no difference in the maternal and fetal morbidity between non colonized and colonized cases. The important finding was that the number of hours in labour was reported as significant risk factor for vaginal colonization (OD 1.02, 95\% CI 1.00$1.03, \mathrm{P}=0.04)$.

Alkire BC et al, have done a study in 2016 where they first did the base line survey audit of 260 deliveries. ${ }^{13} \mathrm{Re}$ Audit was done after implementation of intervention in 250 deliveries. They reported in their study implementing the new criteria improved the diagnosis from $74 \%$ to $81 \%$ $(p=0.049)$ and also the management of obstructed labour from $4.2 \%$ at baseline audit increased to $9.2 \%$ after reaudit $(p=0.025)$. The improvement in detection of prolonged labour by enhanced observation of uterine contractions with cervical dilatation and degree of descent of presenting part, arrested cervical dilation, and severe moulding contributed to improved the diagnosis (all $\mathrm{p}$ <0.04). Patient reviews by senior obstetricians increased from $34 \%$ to $43 \%(p=0.045)$ and reduced time for caesarean section intervention from the median time of 120 to 90 minutes $(\mathrm{p}=0.001)$ improved management (all $\mathrm{p}<0.05)$. Perinatal outcomes, neonatal distress and fresh stillbirths, were reduced from $16 \%$ to. $8.8 \%$ ( $\mathrm{p}=$ $0.01)$.

Mondal S, et al in reported a study done at tertiary care hospital in West Bengal on 313 patients. ${ }^{14}$ Majority of the patients $(87.86 \%)$ were from low socioeconomic group, $88.82 \%$ were from rural areas $16.16 \%$ were illiterate, and
$27.79 \%$ were unbooked. In their study also as in our study commonest cause of obstructed labor was cephalopelvic disproportion (55.59\%). Other causes they reported were malposition (23\%), malpresentation $(18.21 \%)$, fetal congenital abnormality (1.28\%), myoma $(0.32 \%)$, and non-dilatation of cervix $(1.60 \%)$. They also had commonest mode of delivery as cesarean section $(85.94 \%)$. In their study also majority of the cases $(88.82 \%)$ were from rural background, $16.61 \%$ patients were illiterate, $87.86 \%$ patients were of low socioeconomic status, and $27.79 \%$ cases were unbooked.

Gleason RL, et al from ethopia interesting study where they have suggested 3D camera based novel safe, scalable approach to better predict risk of CPD. ${ }^{15}$ They calculated the CPD risk scores based on anthropometry, clinical pelvimetry, MRI, and Kinect measurements which were compared. Significant differences were observed in most anthropometry, clinical pelvimetry, MRI and Kinect measurements between women delivering via CPD-related $\mathrm{C} / \mathrm{S}$ versus those delivering vaginally. Results in their study area under the receiveroperator curve from novel CPD risk scores base on MRI-, Kinect-, and anthropometric-features outperformed novel CPD risk scores based on clinical pelvimetry and previously published indices for CPD risk calculated from these data; e.g., pelvic inlet area, height, and fetalpelvic index.

Wilson reported there was no difference in key outcomes of maternal and perinatal mortality with symphysiotomy when compared with caesarean section. ${ }^{16}$ However they reported there was a reduction in infection ( $\mathrm{rr} 0.30,95 \%$ ci $0.14-0.62$ ) but an increase in fistulae (rr 4.19, 95\% ci 1.07-16.39) and stress incontinence with symphysiotomy (rr 10.04, 95\% ci 3.23-31.21).

\section{CONCLUSION}

Obstructed labor is one of the major cause of maternal and perinatal morbidity. $32 \%$ had developed fever during post operative period $12.5 \%$ cases had wound sepsis and $6 \%$ of cases required re-suturing of wound during post operative period. $28 \%$ of cases had longer stay which was more than 7 days at hospital. Though there was no maternal mortality but had led to fetal morbidity. $44 \%$ of fetus required NICU admission. In $16 \%$ fetus APGAR Score at 5 min was $<7$ and $6 \%$ fetus was IUFD.

Cephalopelvic disproportion was the most common cause for obstructed labor. Timely identification of prolonged labor and timely referral and management can save the life of both baby and mother. Referral to tertiary care centre with Blood Bank and NICU facilities is fore needed.

Funding: No funding sources Conflict of interest: None declared

Ethical approval: The study was approved by the Institutional Ethics Committee 


\section{REFERENCES}

1. Dunea G, Perman E. A royal pregnancy gone wrong birth, pregnancy, and obstetrics. Hektoen International J Human Fall. 2012;4(4). Available at: https://hekint.org/birth-pregnancy-obstetrics/.

Assessed 15 April 2019.

2. World Health Organization. Education material for teachers of midwifery: midwifery education modules. 2nd ed. Managing prolonged and obstructed labor. 2008. Available at: https://apps.who.int/iris/bitstream/handle/10665/4414 5/9789241546669_4_eng.pdf?sequence=4\&isAllowe $\mathrm{d}=\mathrm{y}$. Assessed 6 April 2019.

3. Gessessew A, Mesfin M. Obstructed labour in Adigrat zonal hospital, Tigray Region. Ethiop J Health Dev. 2003;17(3):175-80.

4. Dolea C, AbouZahr C. Global burden of obstructed labour in the year 2000. Evidence and Information for Policy (EIP), World Health Organization, Geneva; 2003:1-17.

5. Cron J. Lessons from the developing world: obstructed labor and the vesico-vaginal fistula. Medscape Gen Med. 2016;5(3):14.

6. Henok A, Asefa A. Prevalence of Obstructed Labour among mothers delivered at Mizan Aman general hospital, South West Euthopia. A Retrospective study. J Womens Health Care. 2015;4(5):1-4.

7. Adeyoe IS, Dimejesi L, Onoho R, Bartholomew O, Ezeanochie M, Kalu C. Obstructed labour South East Nigeria Revisited. A multicenter study on maternal socio demographic and clinical co relates. J Womens Health Care. 2014;3(3):160.

8. Indra, Usharani N, Bendigiri M. A study of clinical outcome of obstructed labor. Int J Reprod Contracep Obstet Gynaec. 2017;6(2):439-42.

9. Ranjana, Sinha A. Incidences, causes and feto maternal outcome of obstructed labour at tertiary health care center. Int J Reprod Contracepm Obstet Gynaec. 2017;6(7):2817- 21.

10. Khatun J, Khanom K. Obstructed labour: A life threatening complications. Med Today. 2017;29(1):12-4.

11. Shaikh SR, Memon KN, Usman G. Obstructed labour; risk factors and outcome among women delivering in a tertiary care hospital. Professional Med J. 2015;22(5):615-20.

12. Ngonzi J, Bebell LM, Bazira J, Fajardo Y, Nyehangane D, Boum Y, et al. Risk Factors for vaginal colonization and relationship between bacterial vaginal colonization and in-hospital outcomes in women with obstructed labor in a Ugandan Regional Referral Hospital. Int J Microbiol. 2018:1-7.

13. Alkire BC, Vincent JR, Burns CT, Metzler IS, Farmer PE, Meara JG. Obstructed labor and caesarean delivery: the cost and benefit of surgical intervention. PLoS One. 2012;7(4):e34595.

14. Mondal S, Chaudhuri A, Kamilya G, Santra D. Fetomaternal outcome in obstructed labor in a Peripheral tertiary care hospital. Med J Dr. D.Y. Patil University. 2013;6(2):146-50.

15. Gleason RL, Yigeremu M, Debebe T, Teklu S, Zewdeneh D, Weiler M, et al. A safe, low-cost, easyto-use 3D camera platform to assess risk of obstructed labor due to cephalopelvic disproportion. PLoS One. 2018;13(9):e0203865.

16. Wilson A, Truchanowicz EG, Elmoghazy D, MacArthur C, Coomarasamy A. Symphysiotomy for obstructed labour: a systematic review and metaanalysis. BJOG. 2016;123:1453-61.

Cite this article as: Bansal A, Kalra R. Feto maternal outcome in obstructed labor: a tertiary centre study. Int J Reprod Contracept Obstet Gynecol 2019;8:2499-505. 